\title{
A case report of broken tip of thrombus aspiration catheter (Thrombuster II) in ectatic left circumflex artery of young patient with Kawasaki disease
}

\author{
Mon M Oo*, Muhammad DB Ismail, Imran Z Abidin and Wan AW Ahmad \\ Cardiology Unit, Department of Medicine, University of Malaya Medical Centre, Malaysia
}

\begin{abstract}
We describe a 29- year old gentleman who presented with acute coronary syndrome, non-ST elevation myocardial infarction. Urgent percutaneous coronary intervention was performed in view of failed medical therapy (ongoing chest pain with dynamic ECG changes). In view of huge thrombus burden in ectatic left circumflex artery, we did thrombus aspiration by using thrombus aspiration catheter (Thrombuster II). After successfully aspirating thrombus, resistance felt on withdrawal of the aspiration catheter from the ectatic coronary artery. Tip of the thrombus aspiration catheter was broken and retained in the guide wire at the level of mid circumflex artery. The broken tip of thrombuster was successfully retrieved percutaneously. This case presents previously unreported complication of thrombus aspiration catheter (Thrombuster II).
\end{abstract}

\section{Introduction}

In ST elevation myocardial infraction (STEMI), percutaneous coronary intervention is superior to thrombolysis in terms of in-hospital mortality, re infarction and stroke [1]. Coronary atherosclerotic plaque rupture with thrombus formation being the basic pathophysiologic phenomenon in acute myocardial infarction, prevalence of thrombus is very much commonly seen in STEMI compare to non-ST elevation myocardial infarction (NSTEMI) [2]. Usage of thrombus aspiration catheter during percutaneous coronary intervention (PCI) for ST elevation myocardial infarction yielded conflicting outcomes. Failed to improve one-year clinical outcome with routine adjuvant thrombus aspiration at the time of PCI in NSTEMI patients [3]. However, individualized approach in managing of acute $\mathrm{MI}$ with huge thrombus burden still promising the usage of aspiration catheter in PCI. Nevertheless, complication may arise and the technique of dealing with it is extremely important as no single technique will be effective at all times. It is worthwhile to be familiar with available technique as well as local center availability. We report a case of broken tip of thrombus aspiration catheter (Thrombuster II) which successfully retrieved percutaneously by using different retrieval techniques in a patient with Kawasaki disease.

\section{Case report}

A previously healthy 29-year old man presented with acute onset of central chest pain, heavy in nature with pain score ranging from 6-7. Pain associated with sweating and dizziness lasting for few hours prior to arrival to emergency department. He was told to have high cholesterol level but not on regular medication or proper follow up. History of similar episode of chest pain 3 years ago, no further investigation was carried out. No family history of coronary artery disease. On examination, the patient was comfortable with no signs of heart failure. Blood pressure noted as $130 / 70 \mathrm{mmHg}$ and pulse rate was $76 \mathrm{bpm}$. Chest X-ray did not show signs of pulmonary congestion.
Electrocardiography (ECG) showed $\mathrm{T}$ inversion in aVL and lead I (Figure 1). Laboratory testing recorded as elevated levels of creatine kinase (391 U/L, normal range 32-294 U/L), Creatine kinase-MB $(18.8 \mathrm{ng} / \mathrm{ml}$, normal range $<5.0 \mathrm{ng} / \mathrm{ml})$ and Troponin I $(1.34 \mathrm{ng} / \mathrm{ml}$, normal range $<0.06 \mathrm{ng} / \mathrm{ml}$ ). Transthoracic echocardiography showed left ventricular ejection fraction of 55\% with hypokinesia noted in mid and basal lateral wall of left ventricle. Aspirin and clopidogrel together with subcutaneous Factor Xa inhibitor was started for acute coronary syndrome treatment. The serial ECG (Figure 2) noted as dynamic changes and persistent chest pain in spite of medical therapy guarded for urgent percutaneous coronary intervention.

Trans-radial coronary angiogram revealed tortuous and aneurysmal dilatation (ectatic vessels) of all three major coronary arteries (Figure $3 a, 3 b$ ) with huge thrombus in the proximal segment of left circumflex (LCx) artery, the culprit lesion was identified. Left coronary system was engaged with XB 3.0 6-French guiding catheter through right radial access with $6 \mathrm{~F}$ sheath. The lesion was crossed by Run through NS floppy (Terumo) hydrophilic 0.014 inches wire. Among different strategies to deal with huge thrombus burden such as Plain Old Balloon Angioplasty (POBA), thrombus aspiration and intracoronary glycoprotein IIb/IIIa inhibitor, we proceeded with thrombus aspiration. Thrombuster II (Kaneka Corporation) thrombus aspiration catheter introduced into the target vessel and suctioning performed. Blood clots aspirated as

*Correspondence to: Mon Myat Oo, Cardiology Unit, Department of Medicine, University of Malaya Medical Centre, 59100 Kuala Lumpur, Malaysia, E-mail: myatoo@ummc.edu.my

Key words: thrombus, acute myocardial infraction, ectatic vessel, aspiration catheter, retained broken piece, retrieval, kawasaki disease, thrombus aspiration catheter (thrombuster), acute coronary syndrome

Received: February 03, 2020; Accepted: February 17, 2020; Published: February 24,2020 


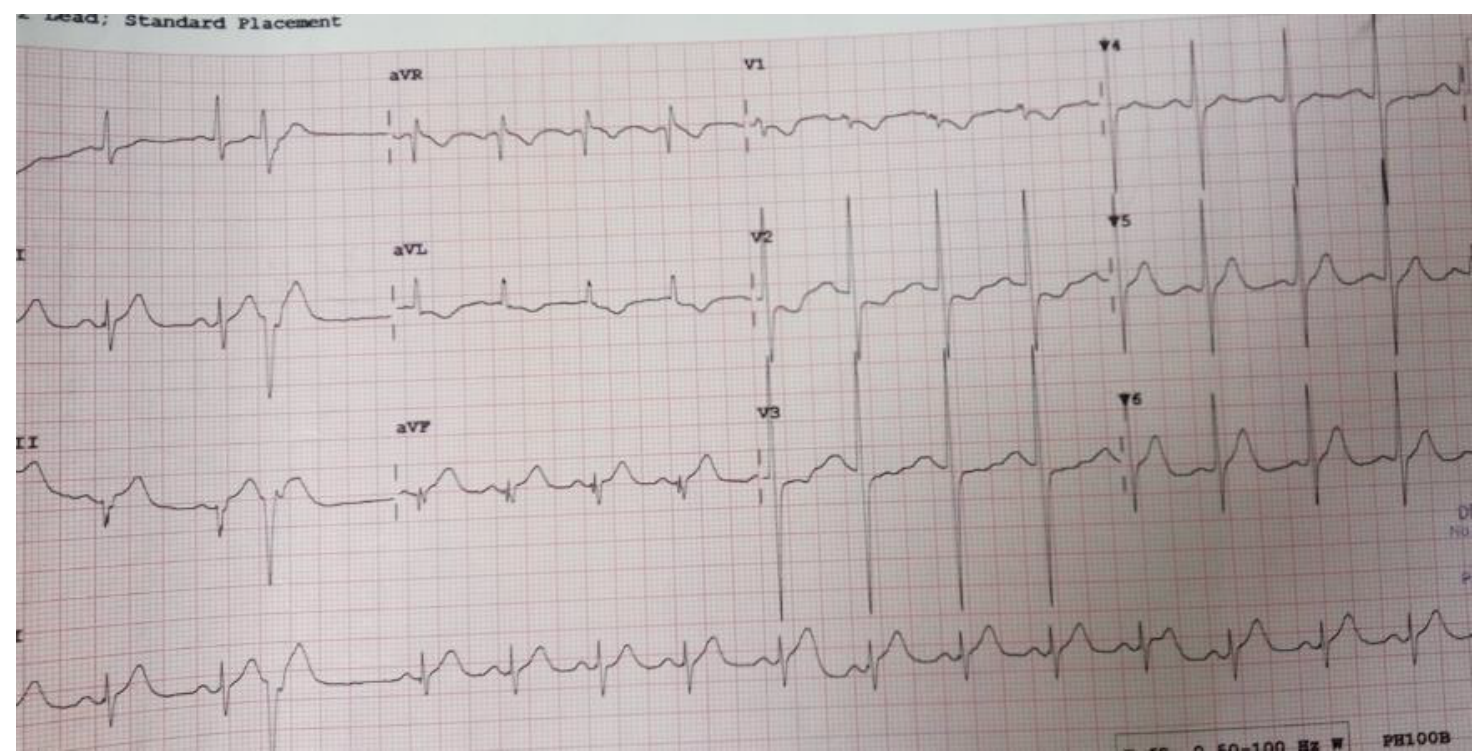

Figure 1. Arrival ECG

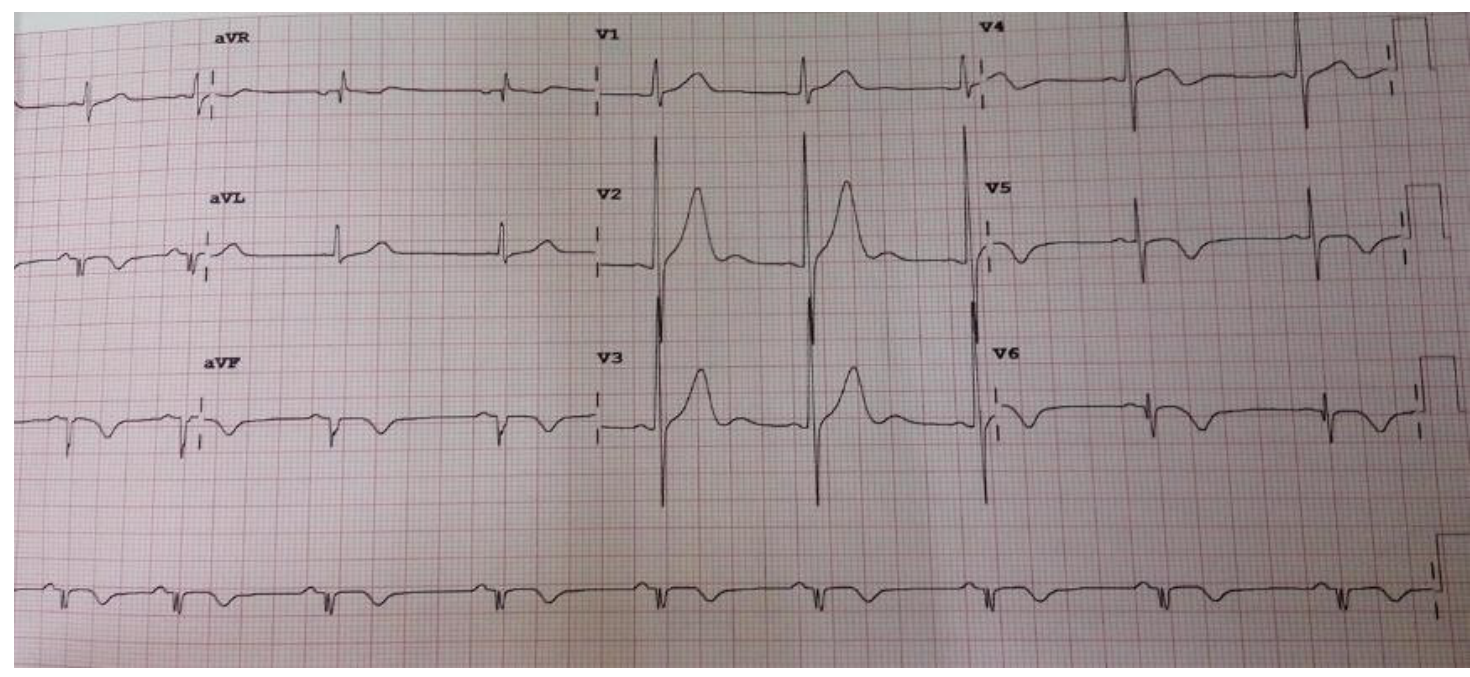

Figure 2. Serial ECG

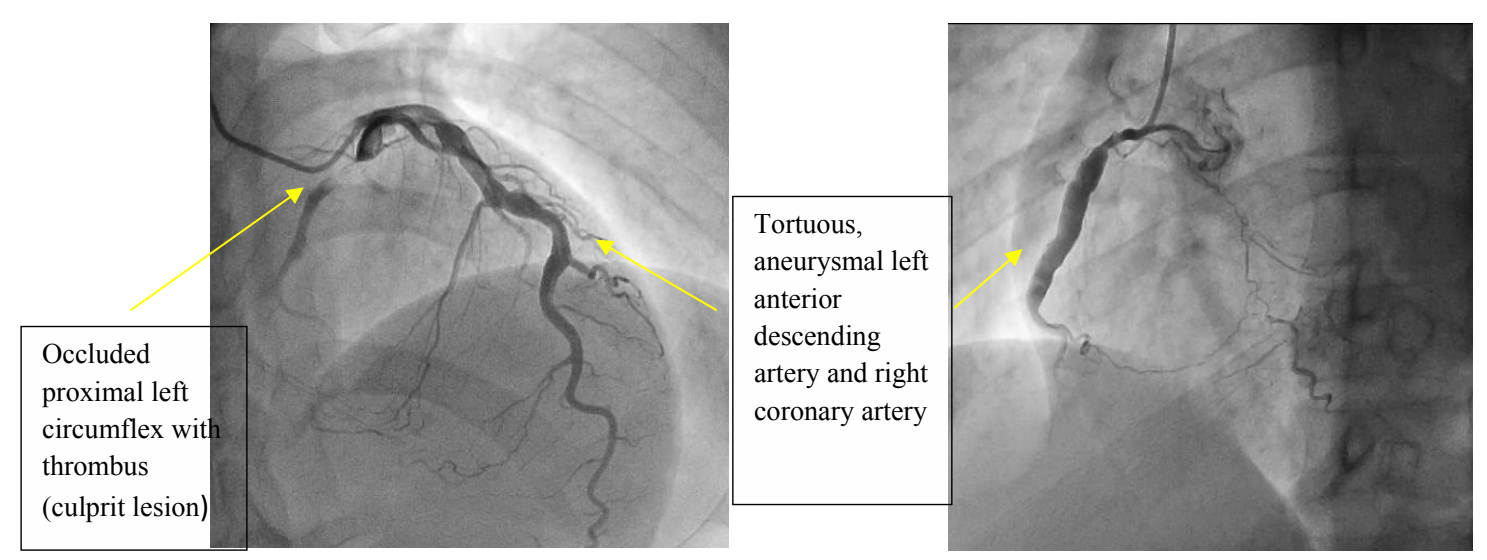

Figure 3a, 3b. Left coronary artery; 3b. Right coronary artery 
shown (Figure 4). After few aspirations, failed to do further suctioning and planned to flush as the catheter may get blocked from aspirated thrombus. Some degree of resistance was felt while removing the catheter from the vessel. The thrombus aspiration catheter finally came out with slight pulling force but noted that the tip was missing (Figure 5). Angiographically, the tip of Thrombuster II catheter seen attached to the guidewire (Figure 6). The guidewire can move freely along the mid and distal LCx but failed to withdrawal at the proximal LCx area.

As the first attempt, we used TREK balloon $2.5 \times 15 \mathrm{~mm}$ anchored in the second run through wire placed in left anterior descending artery (Figure 7) and tried to extract the broken tip. Failed to retrieve with the anchoring balloon technique. The second run through wire was advanced across the LCx and positioned in the distal LCx, twisting parallel wire technique was tried (Figure 8). The broken tip was moving along with the guide wire freely from proximal to distal LCx but failed to pass from the very proximal and ostial LCx. Planned to engulf by using guide catheter extension, Guidezilla (Boston Scientific, USA) has not even failed but resulting in dislodgement further down to distal LCx (Figure 9). Further attempt to trap with low profile TREK $3.0 \times$ $15 \mathrm{~mm}$ by positioning beyond the tip, inflating upto 6 atm pressure (Figure 10) also not working well in retrieving the broken tip. By using various techniques including twisting parallel wire technique, using low profile balloon on another parallel guidewire, reaching out to the tip by using guide catheter extension, Guidezilla (Boston Scientific, USA) has failed and leaving the last option as catching with the snare. The first attempt to snare with $10 \mathrm{~mm} \times 120 \mathrm{~cm}$ snare only dislodged the broken tip more distally. The second snare device $4 \mathrm{~mm} \times 200 \mathrm{~cm}$ Goose Neck Amplatz Microsnare finally managed to capture the guidewire distal to the broken tip (Figure 11) and the whole system was retrieved successfully (Figures 12 and 13). POBA along LCx was

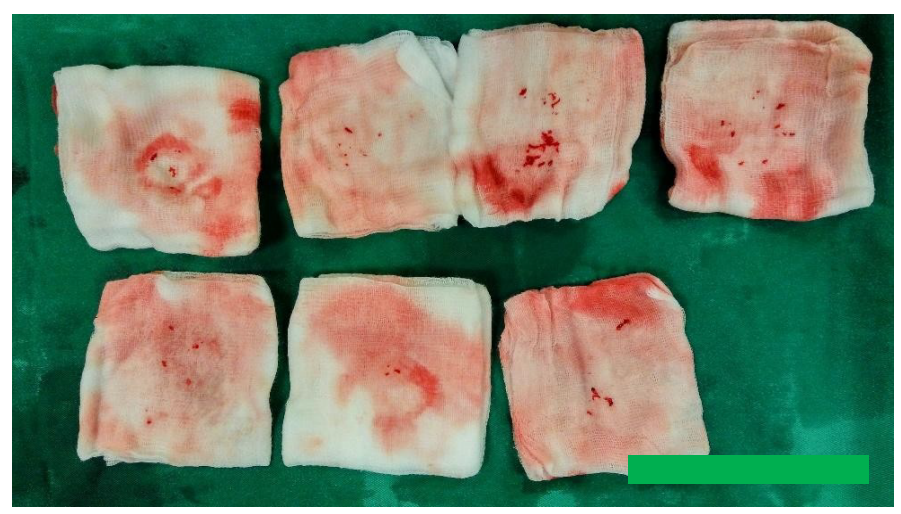

Figure 4. Aspirated thrombus with Thrombuster II

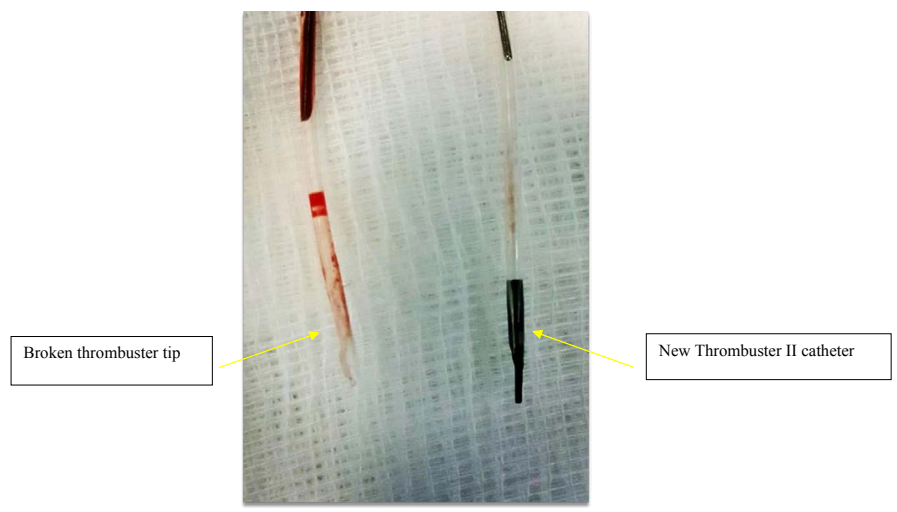

Figure 5. Broken thrombuster II catheter compared with new catheter

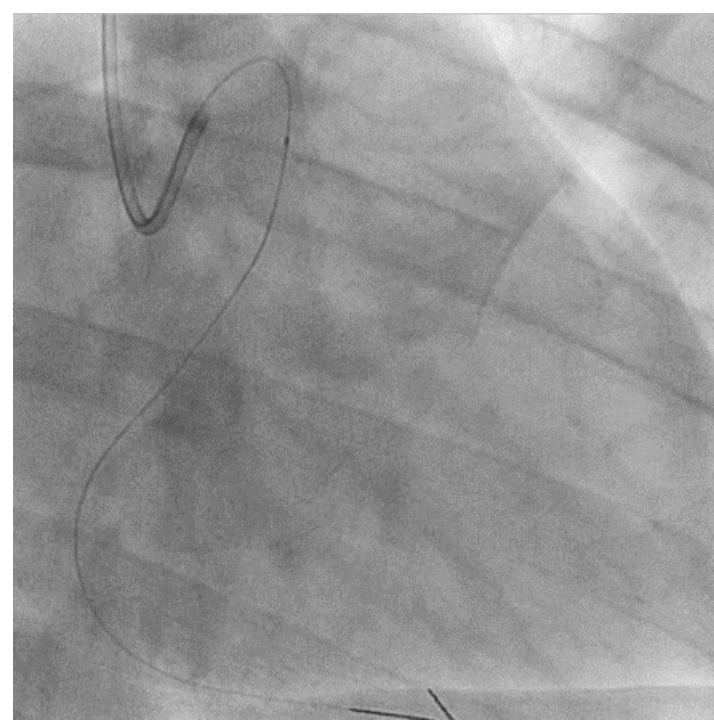

Figure 6. Broken thrombuster II catheter compared with new catheter

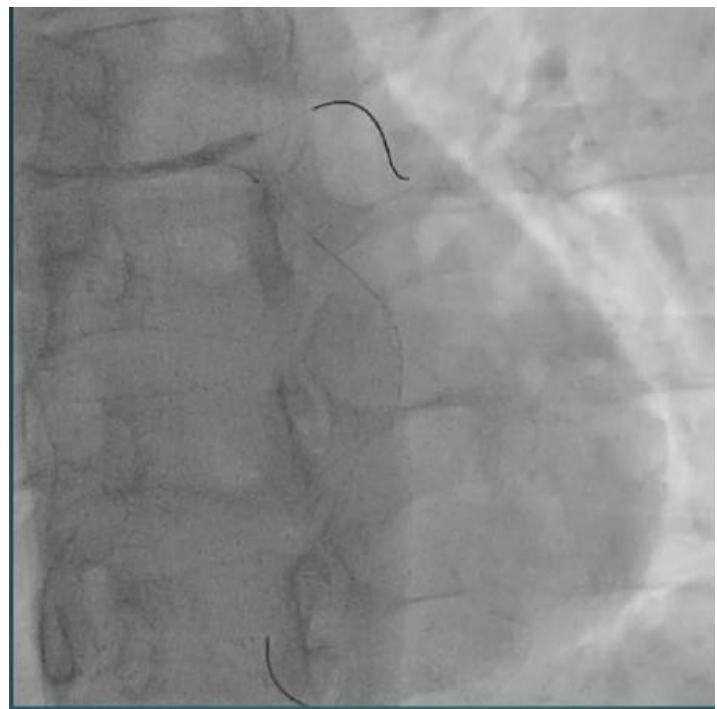

Figure 7. Anchoring balloon technique

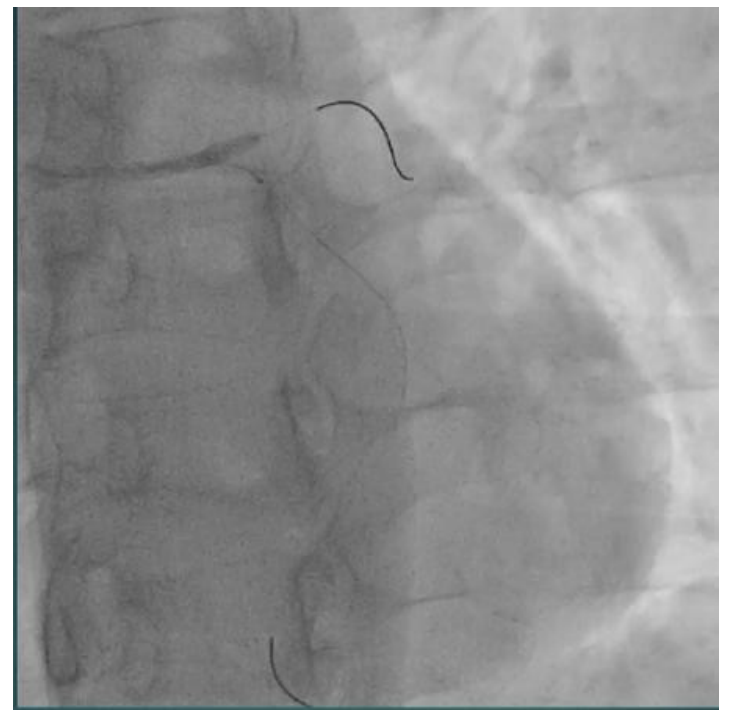

Figure 8. Twisting parallel wire technique 


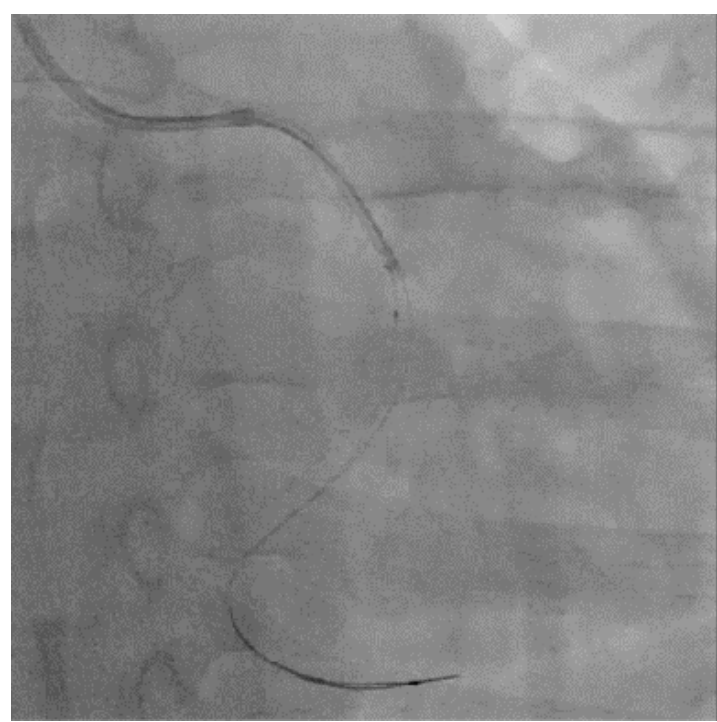

Figure 9. Engulfing with Guidezilla

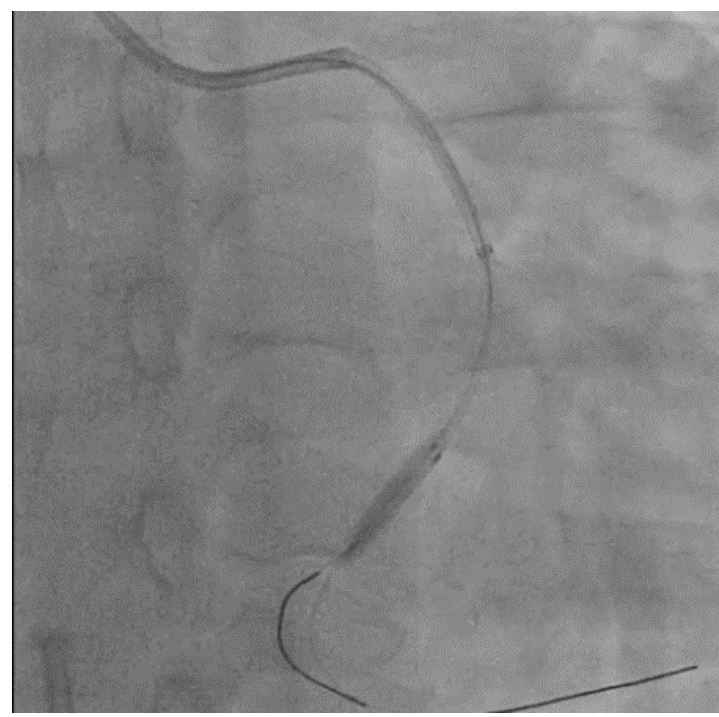

Figure 10. Trapping balloon technique

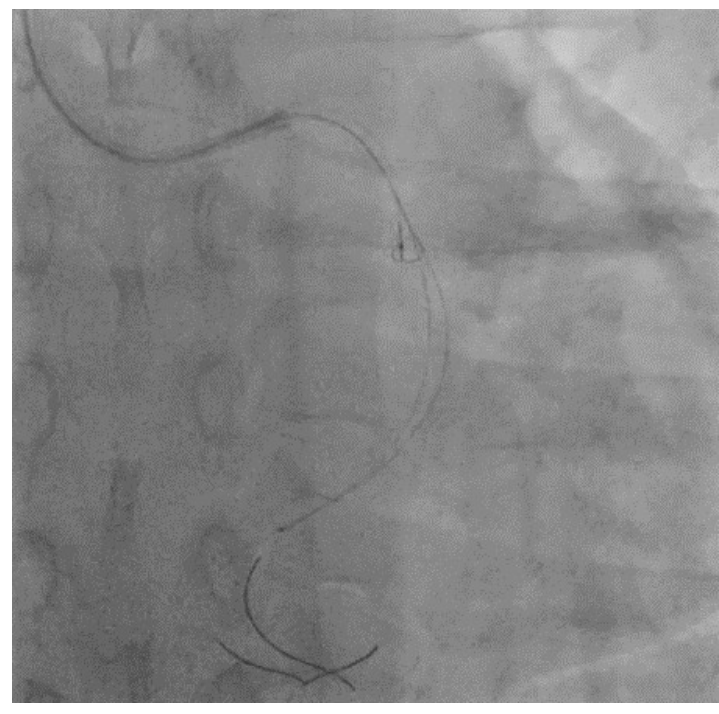

Figure 11. Snaring with Amplatz goose neck

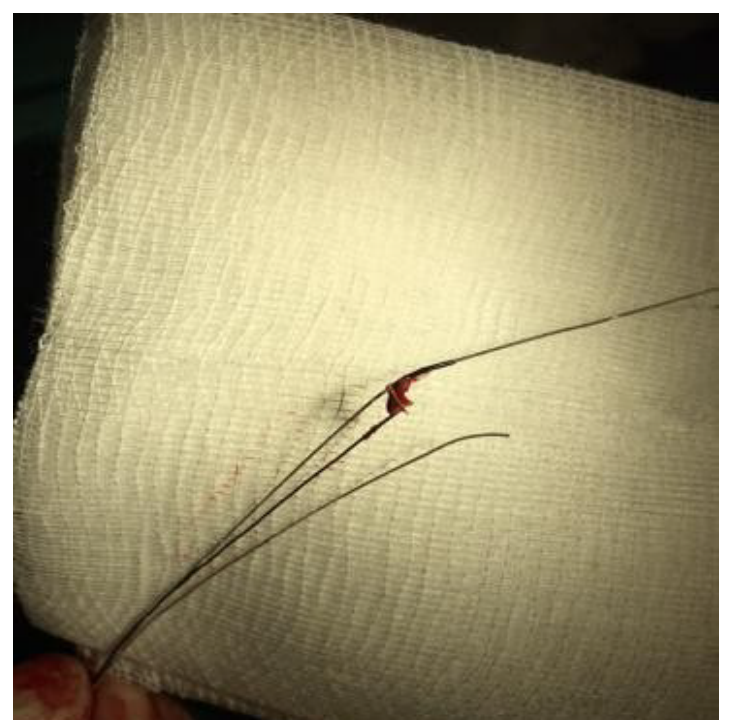

Figure 12. Broken tip attached with the wire

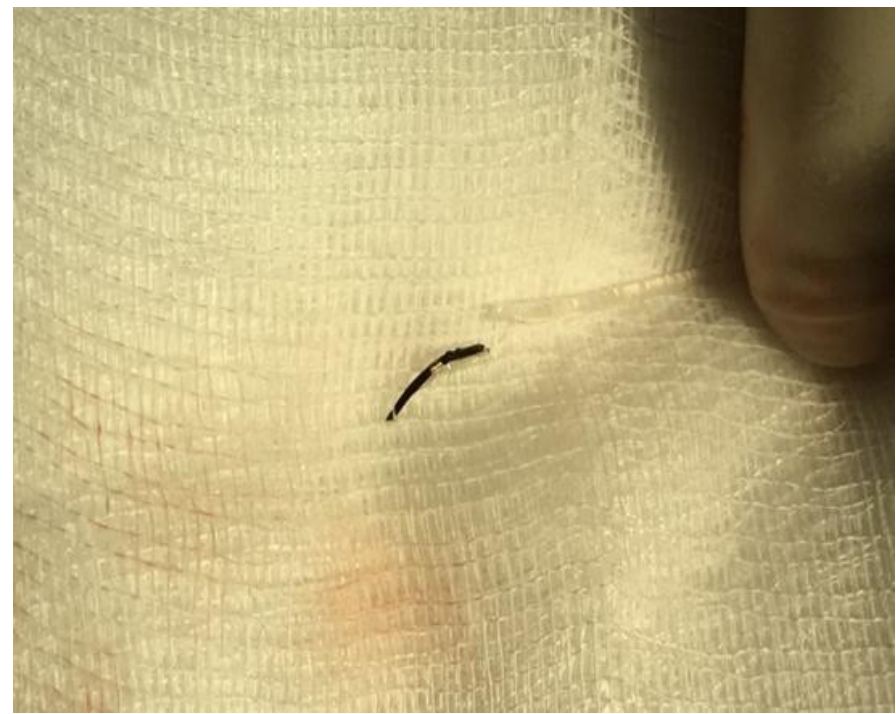

Figure 13. Broken tip and catheter

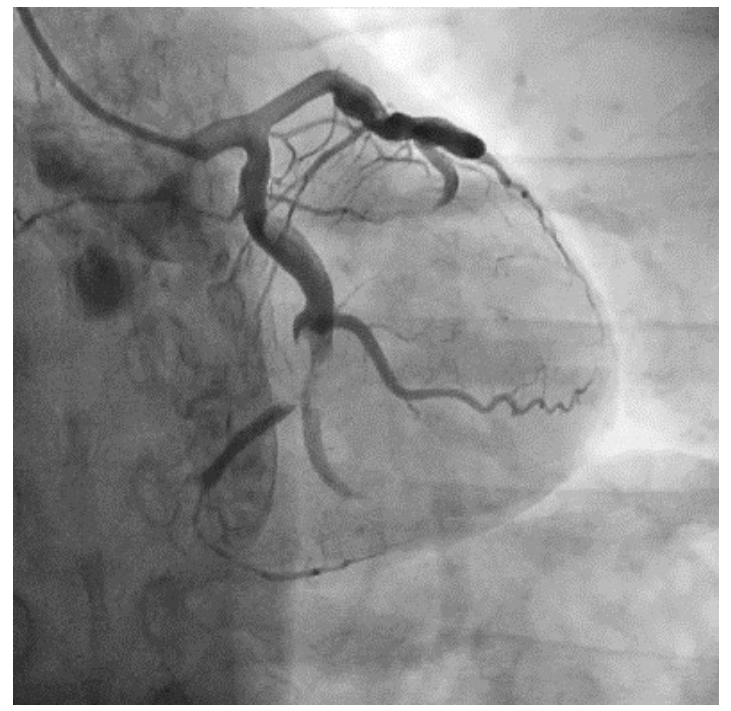

Figure 14. Final angiogram result 
done by using $3.0 \times 15 \mathrm{~mm}$ and upsize to $5.0 \times 15 \mathrm{~mm}$ balloon. Final angiogram revealed flow in the LCx was re-established (TIMI II flow) with no major dissection or perforation was identified (Figure 14). In view of established flow within the ectatic coronary and improving chest pain, we didn't proceed with stenting. The patient was discharged uneventfully after completing 5 days of low molecular weight heparin and discharged with dual antiplatelet therapy, Aspirin and Plavix and non-vitamin $\mathrm{K}$ antagonist oral anticoagulant (NOAC). The patient was reviewed 3 months and 6 months duration, he was asymptomatic with echocardiogram showing left ventricular ejection fraction of $65 \%$ with no regional wall motion abnormality.

\section{Discussion}

In this particular case, we are dealing with thrombus in an ectatic coronary artery in a young gentleman with Kawasaki disease. We experienced fractured tip of thrombus aspiration catheter (Thrombuster II) which was previously unreported complication to our knowledge. Individualized approach in managing patients with huge thrombus burden in acute coronary syndrome still demanding the use of thrombus aspiration catheter in spite of unfavourable outcome for routine use of thrombus aspiration (class III, A recommendation) [4]. The TOTAL trial concluded that routine manual thrombectomy did not reduce the risk of cardiovascular death, recurrent MI, cardiogenic shock, or NYHA class IV heart failure within 180 days but associated with an increased rate of stroke within 30 days according to the total trial [5]. According to the TASTE trial, routine thrombus aspiration before PCI did not reduce 30 -day mortality furthermore no significant differences between two groups ( manual thrombus aspiration before PCI and PCI only) with respect to the rate of stroke or neurologic complications at the time of discharge [6]. Thrombuster II was designated for improved flexibility and smooth insertion into vessel with hydrophilic coating over the first $30 \mathrm{~cm}$ from the tip of the catheter. Improved aspiration was achieved by lowering flow resistance with large and circular aspiration lumen. As only few case reports are recorded, the complication rate of Thrombuster II is unknown. Cagdas Akgullu et al [7] reported a case of trapped thrombus aspiration catheter in coronary artery due to rupture of its main shaft and twisting over the wire which successfully managed to pull out with the whole system. The other case report noted as thrombus in the left main as one of the complications and the other reported an inadvertent coronary endarterectomy with Thrombuster III GR catheter $[8,9]$. The increasing number of percutaneous coronary intervention over few years experiencing increasing number of complication including fracture and retained hardware. The incidence of entrapment and fracture of guidewire is approximately $0.2 \%$ [10]. 48 case reports with total 67 patients experienced guide-wire entrapment - $41.8 \%$ underwent for percutaneous extraction while $43.3 \%$ were managed by surgical and $14.9 \%$ received conservative therapy. Several percutaneous techniques are used such as stenting against the vessel wall, snare loop, double or triple wire technique, bioptome, tornus micro-catheter, deep-guide catheter wedging with balloon inflation and pigtail catheter [11]. According to one of the case reports in the past on prevalence and outcome

of fracture hardware, total twelve patients out of 5400 PTCA procedures experienced different types of retained components such as guidewire fragments, balloon catheter and guide catheter [12]. Follow up on patients with retained wire had no clinical sequelae during follow-up ranging from 6 to 60 months suggesting that decision on attempting to retrieve based on individualized approach. Not all patients with retained hardware need to proceed with CABG especially the thing was retained in totally occluded or distal artery.12
Fractional flow reserve (FFR) wire tip was successfully retrieved with angiographic catheter (Slip - Cath) by using mother-child technique [13]. Successful retrieval of broken export catheter by using balloon inflation was reported previously [14].

Possible causes of most retained hardware include excessive torqueing, forceful withdrawal of catheter, inappropriate handling of catheter, reuse, manufacturing flaws, inadvertent passage of a large catheter through smaller sized access sheaths, polymer aging or a combination of factors. In this case, we analysed that the metal tip of the Thrombuster catheter was broken most likely due to combined factor of undue stress of the catheter tip due to the angulation in the ectatic tortuous coronary artery and the possible twisting of the catheter over the wire. The learning points from this particular complication are as follows; Firstly, it is important to check the aspiration catheter prior to introducing into the guide catheter for possible manufacturer defect. Secondly, it is crucial to have a coaxial guiding catheter engagement, a good support/extra support guide wire, gentle maneuver of the aspiration catheter under good imaging fluoroscopy.

We have to be cautious regarding prolonged and aggressive manipulation in retrieving the retained hardware as it may create complications such as thrombus or air embolization, myocardial ischemia secondary to coronary thrombosis or obstruction, dissection, rupture or perforation of coronary artery leading to pericardial tamponade or emergency cardiac surgery with associated high mortality. There is no randomized trial on anticoagulant/antiplatelet in Kawasaki disease who had acute coronary syndrome and percutaneous coronary intervention. It is based on expert opinion and hospital practice. We use a combination of antiplatelet and anticoagulant for this type of patients. In the past, we used warfarin. The patient was discharged with triple therapy such as aspirin, Plavix and rivaroxaban for 6 months. Based on PIONEER-AF study, we use a combination of Rivaroxaban and clopidogrel as the continuation therapy which shown to be non-inferior to warfarin with regards to bleeding risk.

\section{Conclusion}

We reported a rare complication case of broken tip of thrombus aspiration catheter during percutaneous coronary intervention. Ectatic coronaries are readily seen among active smoker patients in our region. The second most common cause of ectatic coronary vessels being Kawasaki disease as in this particular patient. This case highlighted on familiarity with different retrieval techniques for retained hardware in the coronary artery.

\section{Conflict of interest}

All authors report no conflict of interest

\section{Informed Consent}

Informed consent was obtained from the patient included in this report.

\section{References}

1. Zijilstra F (2003) Angioplasty vs thrombolysis for acute myocardial infraction. Eur Heart $J$ 24: 21-23.

2. Sianos G, Papafaklis MI, Daemen J, Vaina S, van Mieghem CA, et al. (2007) Angiographic stent thrombosis after routine use of drug-eluting stents in ST segment elevation myocardial infarction: the importance of thrombus burden. J Am Coll Cardiol 50: 573583. [Crossref]

3. Meyer-Saraei R, de Waha S, Eitel I, Desch S, Scheller B, et al. (2017) Thrombus aspiration in non-ST-elevation myocardial infarction - 12-month clinical outcome of the randomized TATORT-NSTEMI trial. Eur Heart J Acute Cardiovasc Care 6:10-17. [Crossref] 
4. Lang IM (2018) What is new in the 2017 ESC clinical practice guidelines. Management of acute myocardial infarction in patients presenting with ST-segment elevation: Wien Klin Wochenschr 130: 421-426. [Crossref]

5. Jolly SS, Cairns JA, Yusuf S, Meeks B, Pogue J, et al. (2015) Randomized trial of primary PCI with or without routine manual thrombectomy. N Engl J Med 372: 13891398. [Crossref]

6. Fröbert O, Lagerqvist B, Olivecrona GK, Omerovic E, Gudnason T, et al. (2013) Thrombus aspiration during ST-segment elevation myocardial infarction. $N$ Engl J Med 369:1587-1597. [Crossref]

7. Akgullu C, Eryılmaz U, Gungor H, Zencir C, Avcil M, et al. (2014) A Case of Thrombus Aspiration Catheter Trapped in Coronary Artery Due to Rupture of its Main Shaft and Twisting Over the Wire. J Clin Exp Cardiolog 5:5

8. Alazzoni A, Velianou J, Jolly SS (2011) Left main thrombus as a complication of thrombectomy during primary percutaneous coronary intervention. $J$ Invasive Cardiol 23: E9-11. [Crossref]
9. Taguchi E, Sakamoto T, Kamio T, Kotono Y, Suzuyama H, et al. (2013) Inadvertent coronary endartertctomy during aspiration thrombectomy with a Thrombuster III GR catheter in a patient with acute coronary syndrome. Cardiovasc Interv and Ther 28 : 222-225. [Crossref]

10. G Steffenino, B Meier, L Finci, V Velebit, L von Segesser, et al. (1988) Acute complications of elective coronary angioplasty: a review of 500 consecutive procedures. Br Heart J 59: 151-158. [Crossref]

11. Abdulrahman M Al-Moghairi, Hussein S Al-Amri (2013) Management of Retained Intervention Guide-wire: A Literature Review. Curr Cardiol Rev 9: 260-266. [Crossref]

12. Hartzler GO, Rutherford BD, McConahay DR (1987) Retained percutaneous transluminal coronary angioplasty equipment components and their management. $\mathrm{Am} J$ Cardiol 60: 1260-1264. [Crossref]

13. Prakash S, Mahla H, Bhairappa S, Somanna S, Manjunath C (2015) Successful retrieval of fractured pressure wire tip (FFR) by hybrid technique. J Saudi Heart Assoc 27: 118122. [Crossref]

14. Mehta V, Pandit BN, Trehan V (2013) Retrieval of Broken Export Catheter during primary angioplasty Int J Angiol 22:185-188. [Crossref]

Copyright: $\odot 2020$ Mon M Oo. This is an open-access article distributed under the terms of the Creative Commons Attribution License, which permits unrestricted use, distribution, and reproduction in any medium, provided the original author and source are credited. 